\title{
Enhancing Entrepreneurship Education in a Master's Degree in Computer Engineering: A Project-Based Learning Approach
}

\author{
Enrique Arias $^{1}{ }^{1}$, Virginia Barba-Sánchez ${ }^{2, *}$, Carmen Carrión ${ }^{1}$, and Rafael Casado ${ }^{1}(\mathbb{C}$ \\ 1 Computing Systems Department, University of Castilla-La Mancha, Albacete 02071, Spain; \\ enrique.arias@uclm.es (E.A.); carmen.carrion@uclm.es (C.C.); rafael.casado@uclm.es (R.C.) \\ 2 Department of Business Administration, University of Castilla-La Mancha, Albacete 02071, Spain \\ * Correspondence: virginia.barba@uclm.es
}

Received: 30 June 2018; Accepted: 1 October 2018; Published: 4 October 2018

\begin{abstract}
New master's degrees in computer engineering, designed according to Spanish government requirements, include both technical and business subjects to provide advanced knowledge compared to undergraduate studies. In spite of acquiring this advanced knowledge, our students are not always aware of the significant added value and the positive elements the master's degree provides for their future professional careers. Moreover, we have observed that students regard the different subjects as isolated blocks of knowledge. To tackle these problems, we have carried out a learning experience based on the creation of a technology-based enterprise (TBE) through the development of a common project (CP). Drawing on project-based learning (PBL) methodology, the CP consists of the identification, development, and final oral presentation of a business model. It aims to utilize sensor data and analysis in different domains. The experience has been highly positive, reducing the gap between studies and business practice, and increasing coordination among teachers. A key issue is that all the subjects of the master's degree are involved in this learning experience. In addition, results show a high level of satisfaction with the master's degree, compared to other similar courses.
\end{abstract}

Keywords: entrepreneurship education; active learning; computer science; master's degree education; project-based learning (PBL); technology-based enterprise (TBE)

\section{Introduction}

The process of adapting the Spanish Higher Education System to the European Higher Education Area (EHEA) has had unforeseen consequences (Haug 2015). Among them, it is the false perception of the official master's degree as a mere continuation of an undergraduate degree or an obligatory step for access to doctoral studies. In this sense, according to Haug, in the opinion of graduates and the business sectors that will employ them, master's degrees in Spain lack specific meaning and purpose, being no more than a supplement (without necessarily adding new value) to the corresponding degrees. Specifically, in the context of computer engineering, the low number of students enrolled in official master's degree courses in computer engineering at national level is a common complaint among the Directors of Schools of Computer Engineering (CODDII 2017). Considering these enrollment rates, the continuity of these programs in many Spanish universities may be at risk. Faced with this problem, Haug proposes (without providing specific solutions) the internal strengthening of master's degrees, making them independent programs with their own purpose, relating them to the wider community and employability of the graduates. In this sense, authors such as Hall et al. (2010) or Nabi et al. (2010) point out that economic development is linked to entrepreneurship, with this being key to reducing unemployment (Thurik et al. 2008; Rasmussen et al. 2011). 
Most modern master's degrees in computer engineering were designed to comply with government requirements (Spanish Royal Decree 1393/2007). This Royal Decree lays down the regulations and general conditions to provide the advanced knowledge to be taught in master's degree programs, including both technical and business subjects. However, this Royal Decree reflects, in a somewhat perfunctory manner, the recommendations of the European Commission regarding the inclusion and development of the entrepreneurial spirit in university education (European Commission 2008). In this sense, authors such as Yemini and Haddad (2010) or Barba-Sanchez and Atienza-Sahuquillo (2018) highlight this task of integrating knowledge at current universities as key to their becoming engines of economic and technological development. In addition, students do not perceive the benefits of this advanced knowledge, and, consequently, are not aware of the usefulness of master's programs when compared to the professional skills associated with undergraduate studies.

Within this context, the master's degree in Computer Engineering (MCE) coordination team at the School of Computer Engineering in Albacete promoted entrepreneurship through the undertaking of a common project $(\mathrm{CP})$ that combines all the subjects taught. In particular, the coordination team proposed the creation of a technology-based enterprise (TBE), with a double aim: to develop the entrepreneurial skills of our students, while giving the master's degree a practical, concrete, and useful approach that improves the image students have of the course. The $\mathrm{CP}$ is developed during the two semesters of a master's course. Students produce a business plan with a viable product that may be implemented in the current market.

Thus, this paper provides two main contributions. First, we describe and evaluate the experience of entrepreneurial education implemented in this work. Many previous research papers describe entrepreneurship education programs (EEPs) (Maritz 2017), but are usually in the specific field of business (DeTienne and Chandler 2004; Musteen et al. 2018); or specific educational actions to promote entrepreneurship in other areas (Lans et al. 2013; Barba-Sanchez and Atienza-Sahuquillo 2018). There are a few works that develop a comprehensive program of entrepreneurship in the field of engineering (Hogue et al. 2011; Marvel 2013).

The challenge addressed in this entrepreneurship education experience is the harmonization and co-ordination of the subjects comprising the master's degree in Computer Engineering (MUii 2017) at the School of Computer Engineering (ESII 2017) at the University of Castilla-La Mancha (UCLM 2017). This challenge has been addressed in similar experiences like that described by Hogue et al. (2011). However, in their work, the study plan was specifically designed to develop entrepreneurial skills, which is not our case, and to develop a game, not a TBE as we do. Undoubtedly, from the point of view of a learning and research experience, a clear contribution of this paper is a set of ideas on how to develop entrepreneurial skills through the creation of a TBE involving both technical subjects (Cloud Computing, Internet of Things, etc.) and business subjects. Consequently, this study could serve as guidance to teachers or those responsible for developing or designing a study plan for postgraduate studies in Computer Engineering.

Second, with the results obtained during the implementation of the $\mathrm{CP}$, we propose a model to measure student satisfaction and loyalty of master's graduates. Both variables are the key elements in achieving a successful master's model. Undoubtedly, those responsible for the design and implementation of postgraduate studies, both public and private, will be interested in improving the level of success of these studies in order to make the investments made in this type of university studies profitable, both economically and socially. The proposed model can serve us as a base for future research in this field, considering the different variables to be taken into account when a new learning methodology is applied, and considering that there are a few empirical works in this area.

The structure of the paper is as follows. Section 2 presents work related to project-based learning in human capital development and Section 3 briefly introduces the main characteristics of the master's degree program. Section 4 then describes how project-based learning (PBL) has been applied in the master's degree. Section 5 presents the assessment methodology while, in Section 6 the educational 
results of the implemented approach are analyzed from a qualitative point of view. Finally, some conclusions and future work are presented in Section 7.

\section{Related Work: Project Based Learning Approach on Human Capital Development}

According to Marvel (2016), the development of human capital is strongly linked to entrepreneurial spirit as it helps to discover, create and exploit business opportunities, as well as contributing to the creation of competitive advantages based on the accumulation of new knowledge for new companies. Human capital must be understood as the accumulation of both general and specific knowledge, skills and experience that enable people to generate economic value (Marvel 2013).

The specialized literature (Dimov and Shepherd 2005; Zarutskie 2010) distinguishes between general human capital, useful for any economic activity, and specific human capital, which is limited to a specific sector of activity. In particular, according to Marvel (2013), the general human capital of potential technological entrepreneurs is studied using both formal education and depth of experience.

In this sense, EEPs affect the development of human capital, contributing to the generation of value and wealth for society. For this work, we consider entrepreneurship education (EE), following Fayolle et al. (2006, p.702), as "any pedagogical program or process of education for entrepreneurial attitudes and skills, which involves developing certain personal qualities". However, authors such as Gorman et al. (1997) or Jones et al. (2014) point out that there is a need to differentiate between EE and enterprise education, given that it is not the same to provide students with the skills necessary to create a company as to increase their capacity to generate entrepreneurial ideas. Goldsby et al. (2017) provide us with a four-step guide to finding and creating business opportunities based on the "outsider's perspective" or the non-insider in a certain sector of activity. In addition, as suggested by Gorman et al. (1997), the fact that we achieve an increase in the entrepreneurial intention of our students does not necessarily mean that we are making them better entrepreneurs. For all these reasons, we focus on EE, although we also encourage creative thinking and the generation of ideas, as a basis for this EE.

Furthermore, not all EEPs are equally effective. In this sense, Honing (2004) considers the differences between the conventional view of EE and the experiential model, as opposed to the contingency model. The method of the first two models is based on convergent thinking, from a more traditional view of EE or incorporating experiential trial and error (Kolb and Kolb 2009), in which the solutions are previously designed and in which the students replicate the solutions previously learned. In contrast, the contingency model uses divergent thinking, providing tools that help to adapt to the current dynamic environment characterized by uncertainty and unpredictability. Thus, our proposal for enhancing the entrepreneurship education in the field of Computer Engineering is framed in this contingency model proposed by Honing (2004), using a methodology based on adaptation and the iteration processes of an agile project management methodology (Linden 2018). Hence, we opt for a Project Based Learning Approach.

Since the 1960s, PBL methodology has proved to be one of the most valuable learning methodologies in different fields including medicine, but in particular in the field of science and engineering (Mills and Treagust 2003; Pucher and Lehner 2011; Tseng et al. 2013). According to Swart (2016, p. 99), "PBL is defined as an important method used to help students acquire necessary knowledge, vital skills, and citizenship values for the 21st century; it may be demonstrated through portfolios, performance assessments, and written reports".

Our objective is to reduce the gap between the needs of enterprises and the training of our students in order to increase our graduates' employability. Hence, a learner-centered approach has been implemented in the teaching and learning process to facilitate learner development. This approach includes learning methods based on case studies, problems and projects, helping to create both collaborative learning and a community of practice (Wenger 1998; Barkley et al. 2014; Butler and Christofili 2014; Cukurova et al. 2018). While there are subtle differences between PBL, problem-based 
learning, and case studies, it may be fair to say that each one includes aspects of the others; for example, solving a problem does not necessarily include executing a project in the formal sense (Swart 2016).

Project-based learning is a methodology that allows our students to acquire the knowledge and competencies associated with our current study program while developing the above-mentioned project. The idea underlying this methodology is that the teaching staff act as guides throughout the project and the students are responsible for acquiring knowledge and skills (Savery 2006). The teacher's role is to act as a driving force and learning facilitator more than transmitter of information. In this sense, PBL necessarily leads to critical thinking in order to evaluate different technical solutions, work well in a team and finally search for a good solution that fulfills the initial defined problem. The development of skills is thus implicit in the use of this learning methodology. In PBL, students are active learning elements, which has a positive impact on their performance.

According to English and Kitsantas (2013), PBL methodology emerged from the socioconstructivist theories of learning based on self-directed learning. The student learns through knowledge negotiated with both the teacher and other students (Hmelo-Silver and Barrows 2006). Project-based learning is a teaching methodology based on the development of projects and the resolution of problems by students (Gülbahar and Tinmaz 2006; Hasni et al. 2016). The aim is for the MCE students to play an active role in organizing, scheduling, and implementing a solution that may work in the real world (Blumenfeld et al. 1991). Fini et al. (2017) claim it is very complex to compare different learning models, especially if we focus on comparing learning results. Nonetheless, several authors have highlighted that PBL offers a set of advantages such as improved quality of student knowledge, easier acquisition and application of knowledge, and the development of a positive attitude towards learning, etc. (Blumenfeld et al. 1991; Dochy et al. 2003; Abdelkarim et al. 2016).

However, a number of authors have identified disadvantages that can act as barriers in the implementation of this methodology. These disadvantages arise from the lack of commitment from students, from the vices acquired in traditional education or from time management, especially in out-of-class sessions (Baser et al. 2017).

In addition to the disadvantages mentioned above, Corral Lage and Ipiñazar Petralanda (2014) highlighted the uncertainty generated by the learning system and the fear of expressing ideas that can be refuted. In this sense, according to Glassner and Eran-Zoran (2016), the main drawbacks of PBL are that it is more time-demanding for students and it generates a certain insecurity due to its being a little-known method. Solaz Portolés et al. (2013) also refer to inherent teamwork conflicts, space requirements, and the knowledge and skill required to implement the method. Moreover, this methodology improves students' individual capacities, having a great impact on the final results (Lou and MacGregor 2004). These capacities include, among others, ability to manage time, ability to coordinate and cooperate, leadership and communication skills, and the capacity to analyze information, all of which are skills needed to prepare the students to create an entrepreneurial spirit (Sousa 2018).

Despite computer engineering being a recently-developed field of engineering, a number of noteworthy studies describe the relevance of PBL in this context (Mills and Treagust 2003; Pucher and Lehner 2011; Tseng et al. 2013). For example, Yadav et al. (2011) presented an empirical study on students' perception of PBL in an undergraduate electrical engineering course. The results showed that students were not aware of the knowledge they had acquired through PBL and preferred more traditional teaching techniques. Nevertheless, students thought they had improved both their ability and confidence to solve problems and work in a collaborative way. In the works mentioned above, PBL is defined for one subject or a reduced number of subjects but not for the whole program of studies. So, one of the main challenges addressed in this paper is the harmonization and coordination of all the 10 subjects taught in the MCE program. In this way, Hogue et al. (2011) presented an interesting case study of a PBL framework for a "Game Development and Entrepreneurship Program" that integrates all the core courses in which the students are enrolled. The students, working in teams, are required to develop a fully playable game, including a business plan, a pitch presentation, and a $30 \mathrm{~s}$ trailer. 
The analysis of this PBL approach considers dropout rate, student perceptions, student performance, and the teaching staff's perspective in a similar way as in our proposal. To be more precise, at this point we must highlight that one of the main outcomes of our PBL practical experience is the proposed theoretical model. This model considers students' satisfaction and grades, in a similar way as in Hogue et al. (2011) and Yadav et al. (2011), but also includes willingness to recommend the course. Thus, this study is a step forward in supporting PBL in engineering by building a practical case and using an evidence-based PBL method to propose a theoretical model.

\section{Master's Degree in Computer Engineering: A Brief Description}

The master's degree in Computer Engineering is taught every year at the School of Computer Science Engineering in Albacete (ESII 2017) at the University of Castilla-La Mancha (Spain). The recommended applicant profile requires students have an official university degree linked to the profession of Technical Engineer in Informatics. The MCE is an official master's degree, so it is recognized by the Spanish Ministry of Education, Culture, and Sport, and may be validated across the European Higher Education Area (EHEA).

The objective of the MCE is to enable graduates to lead and coordinate projects, working groups and organizations related to Information and Communication Technologies (ICT), specializing in critical skills and technical capabilities. The master's course content has been developed to equip students with critical IT skills in the following three hot topics: Business Intelligence, Smart Cities, and Big Data and Cloud Computing.

The master's degree in Computer Engineering is offered in two modalities: face-to-face and blended learning. The MCE consists of 90 European Credit Transfer System (ECTS) credits, with 12 ECTS assigned to the module of management and administration, 48 ECTS to the module of Information Technologies (IT), 12 ECTS to a compulsory internship in an enterprise, and 18 ECTS to produce and defend a master's thesis in the area.

The academic year begins in October and ends in June, with the teaching period divided into two semesters. Students enroll in a total of 10 subjects in the first academic year with each subject worth 6 ECTS credits. Table 1 shows the subjects included in the MCE and the semester in which they are taught.

Table 1. Subjects of the master's degree in Computer Engineering (MCE) ${ }^{1}$.

\begin{tabular}{cl}
\hline Semester & \multicolumn{1}{c}{ Subject } \\
\hline \multirow{3}{*}{1 st } & Strategic and Operational Management \\
& Information Technology Governance and Innovation Management \\
& Interaction and Visualization of Information \\
& Technology Integration for Embedded and Ubiquitous Systems \\
& Audit and Security Management \\
& Management Skills \\
& Planning and Management of Information and Communication Technology \\
& Infrastructures \\
& Intelligent Systems Development \\
& High-Performance and High-Availability Computing Services \\
& Management, Certification and Evaluation of Systems and Services \\
\hline & 1 In bold are the keywords which describe the subjects.
\end{tabular}

\section{Project Based Learning Approach to the Master's Degree in Computer Engineering}

The following sections describe, in detail, how PBL has been applied to the master's degree in Computer Engineering. Focusing on the project itself, if we look at the type and content of each subject per semester, the project "Creation of a Technology-Based Enterprise (TBE)" may be organized in two parts, coinciding with the two semesters. In order to narrow down the broad spectrum of issues in 
computer engineering, the lecturers involved in the MCE agreed to focus the TBE on the application of Internet of Things (IoT) in different contexts such as viticulture or the environment. During the second semester, the enterprises clearly evolved.

To carry out this activity, we drew on the framework presented in Maritz and Brown (2013) and in Maritz et al. (2014). The framework proposes seven dimensions for understanding and evaluating entrepreneurship education programs: contextualization, outcomes, objectives, audience, assessment, content and pedagogy.

Although our master's program is in Computer Engineering, we have made a great effort to promote entrepreneurship, and associated entrepreneurial skills, among our students. This is because we focus on the creation of a TBE as the vehicle that makes it possible to introduce both technical and entrepreneurial knowledge and skills.

Following the previously mentioned framework, we have presented this work by contextualizing not only the master's degree in Spain from a general point of view, but also in our school and students' perceptions of the course. In view of the above, it is clear that, at the moment, our audience is the postgraduate students. These students have different personal situations that also affect the master's degree itself and how we develop it. Some of the students can attend lectures while others cannot, either because they are working or they are in other countries. This different situation of students obliges us to offer both traditional (face-to-face) and non-traditional teaching methods (Blended learning, PBL). It is worth noting that the lectures, practical sessions and different activities are complemented by conferences and workshops conducted by experts from the field of entrepreneurship, start-ups, well-established enterprises, etc. These conferences and workshops provide a more realistic view of the business world than academic lectures.

The objectives of the MCE are described in the course accreditation report. These objectives can be summarized simply as providing society with well-trained information technology professionals. In our context, good professionals mean both research and business professionals. In the following sections, the content of each subject contributing to the technology-based enterprise as common project shows that the latest trends in computer science are taught (high-level education that facilitates a career in research), but with a clear orientation towards the creation of an enterprise, and especially towards entrepreneurship training that stimulates the student to contemplate, in the very near future, launching a start-up. In fact, this sowing the seed of a start-up is a clear outcome, together with the acquisition of entrepreneurial skills, the main outcomes of the master's degree.

Regarding the assessment dimension, this work represents only one part of the assessment. Another part is the surveys completed by employers, conversations with the CEOs of regional enterprises and other organisms that act as stakeholders.

We now explain how the activity was developed and the contribution of each subject.

\subsection{Developent of the Activity}

The PBL activity developed during the academic course in MCE was organized following these steps:

1. Problem definition: First, it was necessary to define the problem. Special care was taken at this point to formulate a problem based on a real case since the aim of the MCE is to provide professional skills. Moreover, defining a real case can help students be more engaged and enthusiastic about the project. The problem proposed was the creation of a technology-based enterprise. At this stage of the PBL, professors define the material and degree of involvement in the project. This year, three topics were worked on:

- Control of air quality in specific areas

- Vineyard control and pest avoidance

- Indoor comfort 
2. Formation of working teams and scheduling: Students work in teams. Each student has a different role. The problem is formulated and presented to the students so that the learning process may start. From this point, and until the end of the academic year, students are active elements guided by the teaching staff.

3. Presentation of solutions: Before the end of the first semester, the students explain their solutions and defend their proposals in an oral presentation. The enterprise is defined and key elements are established. At the end of the second semester, students give a final oral presentation. At this point, the services offered are well-defined, and students have developed a real prototype. A more detailed description of the issues resolved through each subject is presented in Section 4.

4. Assessment: The students' work on the project is assessed through each subject. Note that the CP is assessed from different points of view in each subject. Moreover, teachers choose the level of involvement or relevance of the $\mathrm{CP}$ within the objectives of each subject. The effectiveness of the PBL methodology is also evaluated by collecting information from both teachers and students. The main results obtained from this data are shown in Section 6.

\subsection{First Semester Project}

The subjects in the first semester, as seen in see Table 1, serve to organize the content, that is, the skills to be developed in each one and the expected outcomes, considering that this term represents the first steps towards the creation of the company. Consequently, in this first semester, the core aim is to install sensors in different contexts (vineyards, city, homes, etc.), collect data and sell this data to a third party. However, it is key to set up the enterprises correctly from the beginning, with a good business plan and funding, a secure information system, etc.

Thus, it is possible to highlight the following contributions of each subject:

- Interaction and Visualization of Information: The first step in the creation of an enterprise consists of knowing whether the core of the future enterprise represents a niche market or not. In this case, the analysis and visualization of data from different databases is a good tool to obtain this valuable information. This task is carried out jointly with Strategic and Operational Management.

- Strategic and Operational Management: Once the market niche has been established, students need knowledge of how to develop a good business plan, including funding. Some of these issues are addressed in Strategic and Operational Management and other, such as funding, jointly with Information Technology Governance and Innovation Management.

- Information Technology Governance and Innovation Management: In this subject, issues related to funding (both public and private, as well as at international, European, national and regional level) and protection of inventions (intellectual property rights and patents). This subject must be highly coordinated with Strategic and Operational Management.

- Technology Integration for Embedded and Ubiquitous Systems: This subject represents the base technology for the development of the enterprises, that is, IoT in different contexts.

- Audit and Security Management: It is well known that all information systems must have a baseline in security. The best way to guarantee this baseline in security is to design an Information Security Management System. Moreover, it is also important not only to conduct audits but also to know how to manage them. Finally, the information system that supports the enterprises could be affected and it is advisable to ensure business continuity through the development of a plan. All these issues represent the contribution of this subject to the project.

\subsection{Second Semester Project}

During the second semester, students must perceive that the enterprise is evolving. First, the group of students do not sell the data to third party, rather they provide intelligent services through the cloud, on a server. Both the services and the cloud may be certified as a guarantee seal. In addition, the number of workers at the company increases and, therefore, different departments are constituted 
necessitating a project manager and deployment of skills in teamwork, conflict resolution, time and resource management, etc.

Five subjects are taught on the master's program in the second semester and are the vehicle for developing the tasks and skills explained above:

- Management Skills: The enterprise evolves, necessitating the ability to manage a team, skills in project management, conflict resolution, etc. All these topics are covered in this subject.

- Planning and Management of Information and Communication Technology Infrastructures: As previously mentioned, the enterprise must migrate to a cloud platform in order to be able to deal with the high demand for its services. The enterprise now not only acquires data from the sensors and stores all data in a server, but also has to provide intelligent services for decision-makers. Under this new paradigm, the data is stored and processed in a cloud platform with access provided through these intelligent services. In this subject, all issues related to Infrastructure as a Service (IaaS) and Platform as a Service (PaaS) are presented.

- High-Performance and High-Availability Computing Services: This subject addresses all issues related to the software needed to use PaaS to implement services. Evidently, there is a close relationship between this subject and the previous one (Planning and Management of Information and Communication Technology Infrastructures) and also with Intelligent Systems Development. This subject also introduces the concepts and software of High-Performance and High-Availability used in Big Data projects.

- Intelligent Systems Development: All the techniques needed to analyze data to facilitate decision making are developed in this subject. As a result, a service is implemented and accessed by the cloud platform. In this way, the cloud could be seen as a Software as a Service (SaaS). Consequently, all the service levels in a cloud are addressed. In addition, techniques to address Big Data projects are taught.

- Management, Certification and Evaluation of Systems and Services: The system and services implemented in the previous subjects are managed, certified, and assessed in this subject, guaranteeing the quality of both service and platform.

\section{Materials and Methods}

The empirical research carried out is qualitative in nature, mainly focusing on the study of "how things work" (Patton 2015). The methodological design is based on an inductive perspective, searching for the relevant information and following the basic principles of the bibliographical narrative interpretive method (Fincher 2012). According to Polkinghorne (1995, p. 5), "narrative inquiry gathers events and happenings as its data and uses narrative analytic procedures to produce explanatory stories". The analysis of the narrative is useful to study the individual's and group's subjective experiences of people in a given context, focusing on the sequence of events that take place within that group and not only on the variables of the study (Caine et al. 2013). Given its nature, it is usually applied to small groups of individuals that interact in a limited scenario (time and place), as is our case. In this sense, driven by the demand for higher quality and rigor of EE research by authors such as Gorman et al. (1997) or Pittaway and Cope (2007), we have opted for this methodology not with the intention of establishing a causal relationship between EE and entrepreneurial intention, an objective widely studied in the previous specialized literature (Pittaway and Cope 2007), but to investigate the internal process of the development of this EE experience. Working within the relational narrative inquiry space, we will be able to obtain the relevant research questions for future traditional qualitative research.

To carry out this research method, teachers and students have created a scenario where we have shared the day-to-day process of creating and materializing a TBE throughout the academic year. Although we have also complemented this methodology with interviews, since authors such as Fincher (2012) or Patton (2015) consider the use of the qualitative and semi-structured interviews 
appropriate in the context of narrative inquiry. Information was collected on aspects related to the development of the $\mathrm{CP}$ and the student's satisfaction with the overall process.

The sample consists of 12 students grouped into three work teams as seen in Table 2. Sampling was intentional and based on the criterion of representativeness of both the subjects studied and the teaching methods, i.e., the students who had completed all the subjects in the master's program during the 2016-2017 academic year were selected and, in addition, were representative of each of the teaching modalities available in the master's degree: face-to-face and blended learning. We informed all the students about the research objectives, but participation was voluntary. Therefore, the participants can be considered key informants (Patton 2015).

Table 2. Characteristics of the sample.

\begin{tabular}{cccccc}
\hline Id Student & Age & Working & Year of Completion Degree & Modality & Id Team \\
\hline A & 25 & Yes & $2011 / 2012$ & blended learning & 3 \\
B & 21 & No & $2015 / 2016$ & face-to-face & 1 \\
C & 21 & No & $2015 / 2016$ & face-to-face & 1 \\
D & 21 & No & $2015 / 2016$ & face-to-face & 2 \\
E & 21 & No & $2015 / 2016$ & face-to-face & 2 \\
F & 21 & No & $2015 / 2016$ & face-to-face & 2 \\
G & 21 & No & $2015 / 2016$ & face-to-face & 2 \\
H & 21 & No & $2015 / 2016$ & face-to-face & 3 \\
I & 21 & No & $2015 / 2016$ & face-to-face & 1 \\
J & 38 & Yes & $2012 / 2013$ & blended learning & 3 \\
K & 21 & No & $2015 / 2016$ & face-to-face & 1 \\
L & 31 & Yes & $2005 / 2006$ & blended learning & 3 \\
\hline
\end{tabular}

After conducting the interviews, key variables related to student satisfaction in the context of the MCE degree were identified, as shown in Table 3. With these variables, a first measurement instrument (a questionnaire) was created, using a 5-point Likert-type scale. This was administered to the students in order to pre-test them before the massive data collection expected to take place next year. The survey is structured in three parts:

- The first section globally covers the amount of information available, usefulness, work requirement, time commitment, perception of equity in the score obtained, and satisfaction with the $\mathrm{CP}$;

- The second section specifies the contribution of each subject to the overall understanding of the $\mathrm{CP}$, the level of commitment of the respective teaching staff and the work requirement.

- The third section is related to how the teamwork operates.

The results of this pre-test are described and analyzed in detail in Section 6.

Table 3. Overview of the dependent and independent variables.

\begin{tabular}{|c|c|c|c|}
\hline Variables/Construct $^{1}$ & \# Items & Defining Items $^{1}$ & Related Work \\
\hline $\begin{array}{c}\text { Creating a } \\
\text { technology-based } \\
\text { enterprise (TBE) (CE) }\end{array}$ & 1 & $\mathrm{CE}$ : Involvement in $\mathrm{CP}$ & Musteen et al. (2018) \\
\hline Involvement level (LI) & 2 & $\begin{array}{l}\text { LI1: Percentage of grade that depends on } \mathrm{CP}^{2} \\
\text { LI2: Level of involvement of teachers }{ }^{2}\end{array}$ & $\begin{array}{l}\text { Kember and Leung (2009); } \\
\text { Van de Grift et al. (2017) }\end{array}$ \\
\hline Understanding level (LE) & 1 & LE: $\mathrm{CP}$ helps students understand subject ${ }^{2}$ & $\begin{array}{l}\text { Hogue et al. (2011); Kong } \\
\text { et al. (2017) }\end{array}$ \\
\hline Team working (WT) & 2 & $\begin{array}{l}\text { WT1: Student engagement } \\
\text { WT2: Team coordination }\end{array}$ & $\begin{array}{l}\text { Kember and Leung (2009); } \\
\text { Van de Grift et al. (2017) }\end{array}$ \\
\hline Work required (WR) & 2 & $\begin{array}{l}\text { WR1: Volume of work to be got through in } \\
\text { subject }{ }^{2} \\
\text { WR2: Time spent by the student on subject }{ }^{2}\end{array}$ & Ramsden (1991) \\
\hline
\end{tabular}


Table 3. Cont.

\begin{tabular}{ccll}
\hline Variables/Construct $^{\mathbf{1}}$ & \# Items & \multicolumn{1}{c}{ Defining Items $^{\mathbf{1}}$} & \multicolumn{1}{c}{ Related Work $^{\text {IM1: Students' perceptions about usefulness of }}$} \\
\hline Image of MCE(IM) & 3 & $\begin{array}{l}\text { MCE } \\
\text { IM2: Clear goals in CP } \\
\text { IM3: Teacher coordination }\end{array}$ & $\begin{array}{l}\text { Ramsden (1991); Li and } \\
\text { Kaye (1998); Hogue et al. } \\
\text { (2011); Yadav et al. (2011) }\end{array}$ \\
\hline Grade (SG) & 2 & $\begin{array}{l}\text { SG1: Student grade of subjects }{ }^{2} \\
\text { SG2: Appropriate assessment perception } \\
\text { (grade/effort) }\end{array}$ & $\begin{array}{l}\text { Ramsden (1991); Hogue et } \\
\text { al. (2011); Yadav et al. } \\
\text { (2011) }\end{array}$ \\
\hline Students' satisfaction & 2 & $\begin{array}{l}\text { SS1: Global satisfaction with CP } \\
\text { SS2: Global satisfaction with MCE }\end{array}$ & Fuente et al. (2010) \\
\hline Students' loyalty (SL) & 2 & $\begin{array}{l}\text { SL1: The student will return to study at our } \\
\text { Faculty } \\
\text { SL2: The student would recommend the MCE }\end{array}$ & Fuente et al. (2010) \\
\hline
\end{tabular}

\footnotetext{
${ }^{1}$ Variables and items have been identified starting from multiple interviews with the student in the narrative inquiry framework. ${ }^{2}$ In these items, information is gathered for all the MCE subjects.
}

\section{Findings and Discussion}

The analysis of the information recorded is structured around a set of variables that shape student satisfaction with the pilot experience of the $\mathrm{CP}$.

Table 4 shows this pilot experience has a positive effect on student satisfaction, mitigating the weaknesses previously detected in the MCE: coordination between teaching staff and the low perception of the usefulness of the program, that is, the added value of the master's degree compared to undergraduate studies.

Table 4. Perception of the groups and average satisfaction.

\begin{tabular}{cccc}
\hline Id Team & Coordination Level $^{\mathbf{1}}$ & Perceived Usefulness Level $^{\mathbf{1}}$ & Satisfaction Level $^{\mathbf{1}}$ \\
\hline 1 & 5 & 2.4 & 2.0 \\
2 & 5 & 4.3 & 3.7 \\
3 & 2 & 2.5 & 1.5 \\
\hline \multicolumn{3}{c}{${ }^{1}$ Average number for the team members. }
\end{tabular}

In the first case, the students valued very positively the efforts made by the teachers in order to provide content, methods or useful tools for the achievement of the $\mathrm{CP}$, utilizing previously designed content for each subject to work on the creation of a TBE. In the words of student C-Id, "the feeling that I have at the end of the semester is that everything is interrelated, and they are not isolated topics", with what the student likes most being "that the different master's subjects are coordinated resulting in a single product".

However, the issue of coordination is still a widespread complaint, essentially due to the lack of prior information about the CP. This aspect must be improved in future years. Undoubtedly, bearing in mind that this is the first time PBL methodology has been implemented to undertake a CP involving the coordination of all the subjects, the results have been, from the point of view of both students and teachers, highly satisfactory. In fact, mean student satisfaction has increased by almost one point, going from 1.58 (out of 5) to 2.4 in just one academic year. According to Fini et al. (2017), the explanation is that applying knowledge to a real case is usually a motivating agent for students, with the subsequent increase in involvement and satisfaction.

Regarding the second major weakness detected, we must say that the perception of students regarding the usefulness of the master's degree has improved considerably compared to the previous year, which may have also resulted in higher student satisfaction, according to authors such as citeauthorB13-admsci-329557 (2003) or Solaz Portolés et al. (2013). In this sense, student A-Id states: "As a global experience it is very good to know what aspects to consider at the time of setting up a company. I think it helps to consolidate all the knowledge obtained" and student K-Id highlights: 
"The feeling at the end of the master's degree of having achieved something completely from scratch". Considering, in addition, that the only innovation introduced in the master's degree, compared to the previous academic year, is the implementation of the $\mathrm{CP}$, we propose to verify the following relationships in future quantitative research:

Proposition 1. Undertaking a CP across all the subjects enhances the image of the master's program among the students, increasing the perception of coordination of subjects and the usefulness of the MCE.

Proposition 2. Undertaking a CP that implements all the subjects of a master's degree increases student satisfaction with the master's degree.

Nevertheless, this matching of subjects and project is modified by the internal working of teams. This was observed during this pilot experience: groups 1 and 2 worked in a coordinated manner, sharing all the tasks equitably, but group 3 had serious difficulties in committing to a $\mathrm{CP}$, as seen in Table 4. In fact, student L-Id had to submit the CP individually. An internal problem related to both how to schedule and implement the $\mathrm{CP}$ led to serious disagreement among the members of the group and thus, the team was finally dissolved.

Proposition 3. The relationship between undertaking $a C P$ and student satisfaction is moderated by the functioning of the work team.

Moreover, we have observed a general improvement in students' grades compared to previous courses when each subject was assessed separately. Setting aside other reasons, such as significant differences in the grades achieved before accessing the master's degree, in the teaching staff of teachers or in the level of work requirement in each subject compared to previous academic years, it seems that the use of PBL improves students' understanding of the content of these subjects, as seen in Table 5, which positively impacts on the grades obtained. This idea is presented in detail in Proposition 4.

Table 5. Relation among work requirement level, time used and the final scores.

\begin{tabular}{cccc}
\hline Id Group & Work Requirement Level $^{\mathbf{1}}$ & Time Used $^{\mathbf{1}}$ & Score $^{\mathbf{1}}$ \\
\hline 1 & 3.0 & 4.5 & 3.0 \\
2 & 4.3 & 4.5 & 4.5 \\
3 & 2.5 & 4.3 & 3.0 \\
\hline
\end{tabular}

${ }^{1}$ Average number for the team members.

Proposition 4. Undertaking a project common to all the master's degree subjects improves the student's grades, thanks to a better understanding of the subjects involved in the project, which acts as a mediating variable in this relationship.

However, as shown in Table 6, the level of involvement of each subject in the CP is not homogeneous, ranging from $0 \%$ to $70 \%$, in terms of percentage of the total grade for the subject.

Consequently, the proposed relationship can be altered by this fact, given that the subjects with greater involvement in the $\mathrm{CP}$ (Infrastructure, Audit, and Strategy) are usually those which the $\mathrm{CP}$ helps students to understand better. Thus, we propose the following:

Proposition 5. The relationship between the completion of a $\mathrm{CP}$ and students' grades in each of the subjects it involves is moderated by the level of involvement of each subject in the $C P$.

In addition, another source of student satisfaction is the grade they are awarded, since it serves as both an indicator of their results and the effectiveness of their work, measured in terms of the effort made. In this case, we deemed it appropriate to obtain information on this variable through the praxis 
of "perception of equity in the grade obtained", as seen in Table 5, given the difficulty of measuring the level of effort made in objective terms. As can be seen, only team 2 fully agrees with the grade awarded, as seen in Table 4, which could explain, among other things, their higher satisfaction. In this sense, we propose the following:

Proposition 6. A better grade in subjects increases student satisfaction.

However, we have observed that the effort students are willing to make is based on their perception of the requirements of each subject, which influences the time they devote to each one. In this sense, student B-Id states: "it seems this teacher thinks we only have his subject", and student F-Id: "although the grade is good, it doesn't make up for all the time spent". As shown in Tables 5 and 6, all the groups consider they devoted the necessary time to the $\mathrm{CP}$, but not all consider the level of work requirement in the CP, nor of some subjects (Interaction \& Visualization, Intelligent and Certification) adequate. Thus, we formulate the following propositions:

Proposition 7. The relationship between the grade and student satisfaction is moderated by the perceived level of work required by the student in each subject.

Finally, the increased student satisfaction and the improved image of the master's degree led to an increase in graduates' intention of recommending it to other students and family members, as well as the intention of choosing the University of Castilla-La Mancha (UCLM), and specifically the School of Computer Engineering, to continue their training. In this sense, student G assures: "I will recommend this master's degree if someone asks me". Thus, we propose the following:

Proposition 8. Higher student satisfaction with the master's degree will positively influence both recommendation of this master's degree to other potential students and students' loyalty as future clients.

Proposition 9. An improved image of the master's degree positively impacts on graduates' recommending the program.

Table 6. Classification of subjects according to their requirement level and student perception.

\begin{tabular}{cccc}
\hline Subject & $\begin{array}{c}\text { Level of Involvement in } \\
\text { a common project (CP) }\end{array}$ & $\begin{array}{c}\text { CP Leads to a Better } \\
\text { Understanding of the Subject }\end{array}$ & $\begin{array}{c}\text { Level of Teacher } \\
\text { Helps to CP 1 }^{\mathbf{1}}\end{array}$ \\
\hline Interaction \& & $5-20 \%(-)$ & $2(-)$ & $2(-)$ \\
Visualization & $>20 \%(+)$ & $>4(+)$ & $>4(+)$ \\
Strategy & $5-20 \%(+)$ & $2-4(+)$ & $2-4(+)$ \\
Innovation & $<5 \%(+)$ & $2(+)$ & $2-4(+)$ \\
Embedded & $>20 \%(+)$ & $>4(+)$ & $>4(+)$ \\
Audit & $5-20 \%(+)$ & $2-4(+)$ & $2-4(+)$ \\
Skills & $>20 \%(+)$ & $2-4(+)$ & $2-4(+)$ \\
Infrastructure & $5-20 \%(+)$ & $2(+)$ & $2(+)$ \\
High-Performance & $5-20 \%(-)$ & $2-4(-)$ & $2(-)$ \\
Intelligent & $5-20 \%(-)$ & $2-4(-)$ & $2(-)$ \\
Certification & 1 &
\end{tabular}

${ }^{1}(+)$ Positive perception; (-) Negative perception.

Figure 1 graphically represents the propositions comprising our model. The model will be empirically tested in future research once we have a larger sample, that is, when more students have completed the program in future academic years. In this sense, we call on the academic and research community to replicate our project and make their contributions both to the model and to its possible empirical validation. 


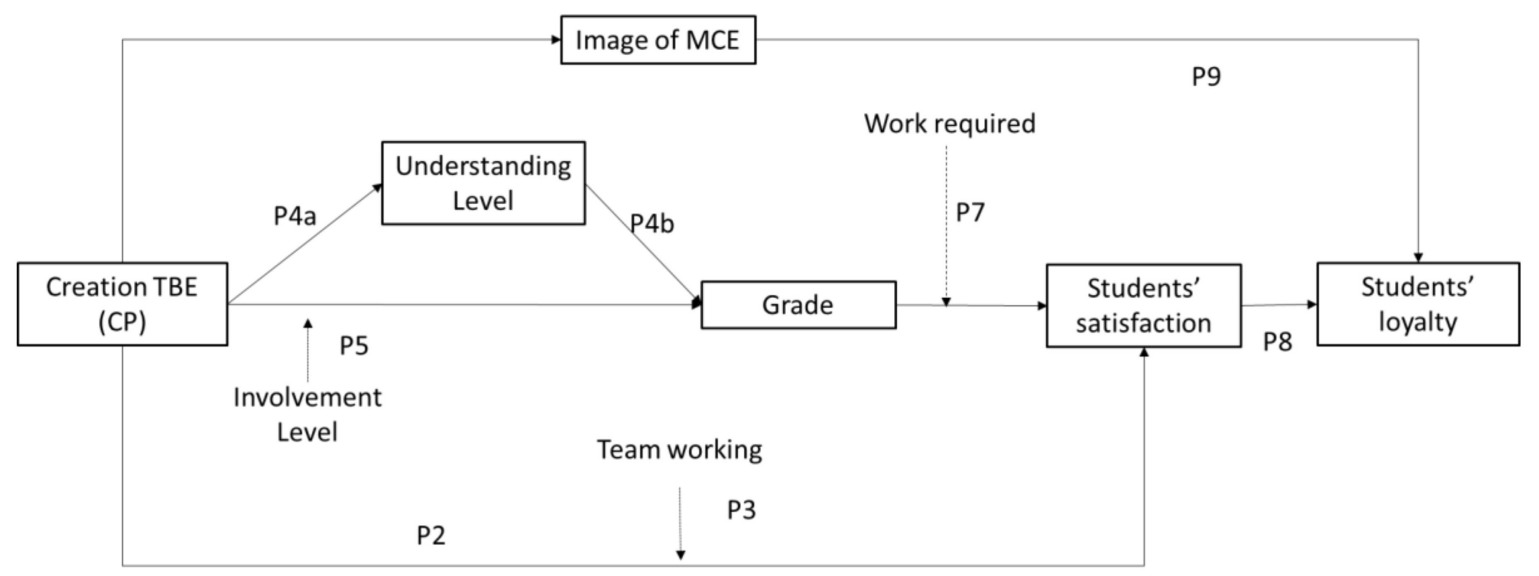

Figure 1. Proposed theoretical model.

\section{Conclusions and Future Work}

In this paper, we describe an EE experience with the implementation of PBL methodology in the master's degree in Computer Science by means of a common project. The overall objective is twofold: (a) to improve the entrepreneurial skills of computer engineers; and (b) to improve the satisfaction and perception of students.

Regarding the first objective, the creation of a technology-based enterprise has allowed the use of an agile project management methodology (Linden 2018). It allows our students to develop divergent thinking, with focus placed on the unmet needs of the potential customer, without losing sight of the requirements of the other stakeholders with power, legitimacy and urgency. This market orientation has provided computer engineers with a broad view of the complexity of the environment and the role they must assume as entrepreneurs. This market orientation has provided computer engineers with a broad view of the complexity of the environment and the role they must assume as entrepreneurs. The permanent adaptation to the environment demanded in this EE experience, based on the contingency model of Honing (2004), has resulted in viable and competitive TBE projects. A further positive outcome is the acquisition of a set of competencies currently in high demand by companies, such as the ability to work in teams and a strong background in management skills, given the nature of the work to be developed: ideation, design, development and implementation of a CP to all the subjects of the master's degree, which consisted of the creation of a TBE.

In this sense, the $\mathrm{CP}$ has proved to be a useful tool to give the student an comprehensive vision of the master's degree, focusing the coordinated effort of all the subjects to obtain the TBE as main output, and, in addition, to introduce hot topics in Computing Engineering in a simple and practical way. These hot topics are essentially Internet of Things, Cloud Computing, Big Data, Business Intelligence, and Cybersecurity, although Smart Cities could also be considered another hot topic covered in the MCE. A smart city refers to a local entity with a large variety of sensors and actuators (IoT) sending a high volume of heterogeneous data from different sources (Big Data), to a cloud platform (Cloud Computing) to be processed and providing signs to decision-makers (Business Intelligence applied to a city).

This EE experience has also served to achieve better coordination across subjects. The coordination of teachers is, undoubtedly, a necessary requirement for the success of this experience, but it is not enough. Other factors to consider, as indicated in the specialized literature (Hogue et al. 2011; Yadav et al. 2011), are students' perception and academic results. However, given the shortage of similar practical work and the difficulty in evaluating this type of experience, we have used narrative inquiry to delve deeply into the experience of our students, proposing additional factors that can affect the success of this type of experience. In this sense, the level of involvement of each subject/teacher in the EE experience, the functioning of the work team, the workload to be carried out, and the students' 
perception of the level of demand, can improve the explanation of the level of satisfaction of the students and their loyalty.

Consequently, with respect to the second proposed objective, and according to the proposed model and the results presented here, the $\mathrm{CP}$ has indeed improved student satisfaction. Hence, we hope it has a positive impact in the near future in terms of enrollment.

However, as in any new experience, we have detected a series of shortcomings that should be addressed. Thus, applying the PDCA (plan-do-check-adjust) improvement cycle, the following corrective actions will be implemented in the coming academic year:

- Improving the information on the $\mathrm{CP}$ provided to the student when introducing each subject. Students would like to be informed about the exact contribution of each subject at onset of the $\mathrm{CP}$; not only for the first semester subjects but also for those of the second semester.

- Emphasizing coordination across and within subjects.

- Proposing the same project in the same sector for different groups of students, to eliminate the perception of "disadvantage" if different sectors are considered.

Finally, one of the main limitations of this work is that it has focused on the students' experience. Without a doubt, a multi-focus analysis, analyzing the experience of the professors and the institution, as proposed by Hogue et al. (2011) would be interesting and enriching to complete the proposed model as seen in Figure 1. In addition, this model seeks to synthesize the conclusions obtained in propositions, which must be corroborated by future quantitative research. In this sense, we invite the researchers in this field to propose hypotheses in this regard to reaffirm or, if necessary, redefine the proposed model, both in the field of computer engineers, and in the field of other professionals, in which the entrepreneurship development is also a social demand.

Author Contributions: Conceptualization, E.A., V.B.-S. and C.C.; Formal analysis, V.B.-S.; Methodology, V.B.-S. and C.C.; Project administration, E.A.; Validation, R.C.; Visualization, R.C.; Writing-original draft, V.B.-S. and C.C.; Writing-review \& editing, E.A., C.C. and R.C.

Funding: This research received no external funding.

Acknowledgments: The authors are very grateful for cooperation received from the teachers and students who took part in this project. The authors would also like to express their gratitude for the support granted by the management team at University of Castilla-La Mancha's High-School Computer Science.

Conflicts of Interest: The authors declare no conflict of interest.

\section{References}

Abdelkarim, Ahmad, Dorothy Schween, and Timothy Ford. 2016. Implementation of Problem-Based Learning by Faculty Members at 12 U.S. Medical and Dental Schools. Journal of Dental Education 80: 1301-7. [PubMed]

Barba-Sanchez, Virginia, and Carlos Atienza-Sahuquillo. 2018. Entrepreneurial intention among engineering students: The role of entrepreneurship education. European Research on Management and Business Economics 24: 53-61. [CrossRef]

Barkley, Elizabeth F., K. Patricia Cross, and Claire H. Major. 2014. Collaborative Learning Techniques: A Handbook for College Faculty. San Francisco: Jossey-Bass.

Baser, Derya, M. Yasar Ozden, and Hasan Karaarslan. 2017. Collaborative project-based learning: An integrative science and technological education project. Research in Science E Technological Education 35: 17.

Blumenfeld, Phyllis C., Elliot Soloway, Ronald W. Marx, Joseph S. Krajcik, Mark Guzdial, and Annemarie Palincsar. 1991. Motivating Project-Based Learning: Sustaining the Doing, Supporting the Learning. Educational Psychologist 26: 369-98. [CrossRef]

Butler, Alison, and Monica Christofili. 2014. Project-based learning communities in developmental education: A case study of lessons learned. Community College Journal of Research and Practice 38: 638-50. [CrossRef]

Caine, Vera, Andrew Estefan, and D. Jean Clandinin. 2013. A return to methodological commitment: Reflections on Narravive Inquiry. Scandinavian Journal of Educational Research 57: 574-86. [CrossRef]

CODDII. 2017. The Confederation of Directors and Deans of School of Computing Engineering. Available online: http: / / coddii.org (accessed on 20 November 2017). 
Corral Lage, Javier, and Izaskun Ipiñazar Petralanda. 2014. Aplicación del aprendizaje basado en problemas en la asignatura contabilidad financiera superior: Ventajas y desventajas. Tendecias Pedagócias 23: 45-60.

Cukurova, Mutlu, Judith Bennett, and Ian Abrahams. 2018. Students' knowledge acquisition and ability to apply knowledge into different science contexts in two different independent learning settings. Research in Science $\mathcal{E}$ Technological Education 36: 17-34. [CrossRef]

DeTienne, Dawn R., and Gaylen N. Chandler. 2004. Opportunity Identification and Its Role in the Entrepreneurial Classroom: A Pedagogical Approach and Empirical Test. Academy of Management Learning and Education 3: 242-57. [CrossRef]

Dimov, Dimo P., and Dean A. Shepherd. 2005. Human capital theory and venture capital firms: Exploring home runs and strike outs. Journal of Business Venturing 20: 1-21. [CrossRef]

Dochy, Filip, Mien Segers, Piet Van den Bossche, and David Gijbels. 2003. Effects of problem-based learning: A meta-analysis. Learning and Instruction 13: 533-68. [CrossRef]

English, Mary C., and Anastasia Kitsantas. 2013. Supporting Student Self-Regulated Learning in Problem- and Project-Based Learning. Interdisciplinary Journal of Problem-Based Learning 7: 128-50. [CrossRef]

ESII. 2017. School of Computing Engineering. Available online: http://esiiab.uclm.es (accessed on 19 November 2017).

European Commission. 2008. Entrepreneurship in Higher Education, Especially in Non-Business Studies. In Directorate-General for Enterprise and Industry. Unit E.1: Entrepreneurship. Available online: http:/ /ec. europa.eu/enterprise/entrepreneurship/support_measures/training_education/entr_highed.pdf (accessed on 13 September 2018).

Fayolle, Alain, Benoit Gailly, and Narjisse Lassas-Clerc. 2006. Assessing the impact of entrepreneurship education programmes: A new methodology. Journal of European Industrial Training 30: 701-20. [CrossRef]

Fincher, Sally. 2012. Using Narrative Methodology. Canterbury: University of Kent at Canterbury.

Fini, Elham H., Faisal Awadallah, Mahour M. Parast, and Taher Abu-Lebdeh. 2017. The impact of project-based learning on improving student learning outcomes of sustainability concepts in transportation engineering courses. European Journal of Engineering Education 43: 473-88. [CrossRef]

Fuente, Hanns, Mercedes Marzo, and María Jesús Reyes. 2010. Analysis of satisfaction of students of the Faculty of Engineering of University of Talca. Ingeniare 18: 350-63.

Glassner, Amnon, and Yael Eran-Zoran. 2016. Place-based learning: Action learning in MA program for educational practitioners. Action Learning: Research and Practice 13: 23-37. [CrossRef]

Goldsby, Michael G., Donald F. Kuratko, Matthew R. Marvel, and Thomas Nelson. 2017. Design-Centered Entrepreneurship: A four stage iterative process for opportunity development. Journal of Small Business $\mathcal{E}$ Entrepreneurship 29: 477-90.

Gorman, Gary, Dennis Hanlon, and Wayne King. 1997. Some research perspectives on entrepreneurship education, enterprise education and education for small business management: A ten-year literature review. International Small Business Journal 15: 56-77. [CrossRef]

Gülbahar, Yasemin, and Hasan Tinmaz. 2006. Implementing project-based learning and e-portfolio assessment in an undergraduate course. Journal of Research on Technology in Education 38: 309-27. [CrossRef]

Hall, Jeremy K., Gregory A. Daneke, and Michael J. Lenox. 2010. Sustainable development and entrepreneurship: Past contributions and future directions. Journal of Business Venturing 25: 439-48. [CrossRef]

Hasni, Abdelkrim, Fatima Bousadra, Vincent Belletête, Ahmed Benabdallah, Marie-Claude Nicole, and Nancy Dumais. 2016. Trends in research on project-based science and technology teaching and learning at K-12 levels: A systematic review. Studies in Science Education 52: 199-231. [CrossRef]

Haug, Guy Eugène. 2015. Grados y Másteres en España y el Espacio Europeo de Educación Superior (EEES). Madrid: CRUE Universidades Españolas.

Hmelo-Silver, Cindy E., and Howard S. Barrows. 2006. Goals and strategies of a problem-based learning facilitator. Interdisciplinary Journal of Problem-Based Learning 1: 21-39. [CrossRef]

Hogue, Andrew, Bill Kapralos, and Francois Desjardins. 2011. The role of project-based learning in IT: A case in a game development and entrepreneurship program. Interactive Technology and Smart Education 8: 120-34. [CrossRef]

Honing, Benson. 2004. Entrepreneurship eduction: Toward a model of contingency-based business planning. Academy of Management Learning \& Education 3: 258-73. 
Jones, Colin, Harry Matlay, Kathryn Penaluna, and Andy Penaluna. 2014. Claiming the future of enterprise education. Education + Training 56: 764-75. [CrossRef]

Kember, David, and Doris Leung. 2009. Development of a questionnaire for assessing students' perceptions of the teaching and learning environmentand its use in quality assurance. Learning Environments Research 12: 15-29. [CrossRef]

Kolb, Alice Y., and David A. Kolb. 2009. Experiential Learning Theory: A dynamic, holistic approach to management learning, education and development. In The handbook of Management Learning, Education and Development. Edited by Steven Armstrong and Cynthia Fukami. Thousand Oaks: Sage, pp. 42-68.

Kong, Xiang T.R., Gao Wei Chen, George Q. Huang, and Hao Luo. 2017. Ubiquitous auction learning system with TELD (Teaching by Examples and Learning by Doing) approach: A quasi-experimental study. Computers $\mathcal{E}$ Education 111: 144-57. [CrossRef]

Lans, Thomas, Karine Oganisjana, Marge Täks, and Vitaliy Popov. 2013. Learning for Entrepreneurship in Heterogeneous Groups: Experiences from an International, Interdisciplinary Higher Education Student Programme. TRAMES 17: 383-99. [CrossRef]

Li, Rose Yanhong, and Mike Kaye. 1998. A case study for comparing two service quality measurement approaches in the context of teaching in higher education. Quality in Higher Education 42: 103-13. [CrossRef]

Linden, Tanya. 2018. Scrum-based learning environment: Fostering self-regulated learning. Journal of Information Systems Education 29: 65-74.

Lou, Yiping, and S. Kim MacGregor. 2004. Enhancing project-based learning through online between group collaboration. Educational Research and Evaluation 10: 419-40. [CrossRef]

Maritz, Alex. 2017. Illuminating the black box of entrepreneurship education programmes: Part 2. Education + Training 59: 471-82. [CrossRef]

Maritz, Alex, and Christopher R. Brown. 2013. Illuminating the black box of entrepreneurship education programs. Education + Training 55: 234-52. [CrossRef]

Maritz, Alex, Gerrit Anton de Waal, and Chich-Jen Shieh. 2014. Educating Engineers: A Postgraduate Entrepreneurship and Innovation Perspective. International Journal of Engieering Education 30: 291-301.

Marvel, Matthew R. 2013. Human capital and search-based discovery: A study of high-tech entrepreneurship. Entrepreneurship Theory and Practice 37: 403-19. [CrossRef]

Marvel, Matthew R. 2016. Human capital and entrepreneurship research: A critical review and future directions. Entrepreneurship Theory and Practice 40: 599-626. [CrossRef]

Mills, Julie E., and David F. Treagust. 2003. Engineering Education, Is Problem Based Learning the Answer? Australasian Journal of Engineering Education 9: 2-16.

MUii. 2017. Master's Degree in Computing Engineering. Available online: http://esiiab.uclm.esmuii (accessed on 19 November 2017).

Musteen, Martina, Ross Curran, Nuno Arroteia, María Ripollés, and Andreu Blesa. 2018. A Community of Practice Approach to Teaching International Entrepreneurship. Administrative Sciences 8: 56. [CrossRef]

Nabi, Ghulam, Rick Holden, and Andreas Walmsley. 2010. Entrepreneurial intentions among students: Towards a re-focused research agenda. Journal of Small Business and Enterprise Development 17: 537-51. [CrossRef]

Patton, Michael Quinn. 2015. Qualitative Research and Evaluation Methods, 4th ed. Thousand Oaks: Sage Publications.

Pittaway, Luke, and Jason Cope. 2007. Entrepreneurship education-A systematic review of the evidence. International Small Business Journal 25: 479-510. [CrossRef]

Polkinghorne, Donald E. 1995. Narrative configuration in qualitative analysis. International Journal of Qualitative Studies in Education 8: 5-23. [CrossRef]

Pucher, Robert, and Martin Lehner. 2011. Project Based Learning in Computer Science: A Review of More than 500 Projects. Procedia-Social and Behavioral Sciences 29: 1561-66. [CrossRef]

Ramsden, Paul. 1991. A Performance Indicator of Teaching Quality in Higher Education: The Course Experience Questionnaire. Studies in Higher Education 16: 129-50. [CrossRef]

Rasmussen, Einar, Simon Mosey, and Mike Wright. 2011. The Evolution of Entrepreneurial Competencies: A Longitudinal Study of University Spin-Off Venture Emergence. Journal of Management Studies 48: 1314-45. [CrossRef]

Savery, John R. 2006. Overview of problem-based learning: Definitions and distinctions. Interdisciplinary Journal of Problem-Based Learning 1: 3. [CrossRef] 
Solaz Portolés, Joan Josep, Vicente Sanjosé López, and Ángela Gómez López. 2013. Aprendizaje basado en problemas en la Educación Superior: Una metodología necesaria en la formación del profesorado. Didáctica de las Ciencias Experimentales y Sociales 25: 177-86.

Sousa, Maria José. 2018. Entrepreneurship Skills Development in Higher Education Courses for Teams Leaders. Administrative Sciences 8: 18. [CrossRef]

Spanish Royal Decree 1393/2007. Of October 29, por el que se establece la ordenación de las enseñanzas universitarias oficiales. BOE n. $260(2007 / 10 / 30)$.

Swart, Arthur James. 2016. Distance Learning Engineering Students Languish Under Project-Based Learning, but Thrive in Case Studies and Practical Workshops. IEEE Transactions on Education 59: 98-104. [CrossRef]

Thurik, A. Roy, Martin A. Carree, André van Stel, and David B. Audretsch. 2008. Does self-employment reduce unemployment? Journal of Business Venturing 23: 673-86. [CrossRef]

Tseng, Kuo-Hung, Chi-Cheng Chang, Shi-Jer Lou, and Wen-Ping Chen. 2013. Attitudes towards science, technology, engineering and mathematics (STEM) in a project-based learning (PjBL) environment. International Journal of Technology and Design Education 23: 87-102. [CrossRef]

UCLM. 2017. University of Castilla-La Mancha. Available online: http:/ / www.uclm.es (accessed on 20 November 2017).

Van de Grift, Wim JCM, Seyeoung Chun, Ridwan Maulana, Okhwa Lee, and Michelle Helms-Lorenz. 2017. Measuring teaching quality and student engagement in South Korea and The Netherlands. School Effectiveness and School Improvement 28: 337-49. [CrossRef]

Wenger, Etienne. 1998. Communities of practice: Learning as a social system. Systems Thinker 9: 2-3. [CrossRef]

Yadav, Aman, Dipendra Subedi, Mary A. Lundeberg, and Charles F. Bunting. 2011. Problem-based learning: Influence on students' learning in an Electrical Engineering Course. Journal of Engineering Education 100: 253-80. [CrossRef]

Yemini, Miri, and Jehuda Haddad. 2010. Engineer-Entrepreneur: Combining technical knowledge with entrepreneurship education. The Israel case study. International Journal of Engineering Education 26: 1220-1229.

Zarutskie, Rebecca. 2010. The role of top management team human capital in venture capital markets: Evidence from first-time funds. Journal of Business Venturing 25: 155-72. [CrossRef]

(C) 2018 by the authors. Licensee MDPI, Basel, Switzerland. This article is an open access article distributed under the terms and conditions of the Creative Commons Attribution (CC BY) license (http:/ / creativecommons.org/licenses/by/4.0/). 